\title{
Hysteresis Controlled Quadratic Boost Converter Based AC Micro Grid System with Improved Dynamic Response
}

\author{
K.Saravanan, L.Porchelvi, K. Selvakumar
}

\begin{abstract}
Renewable power generation and enabling of AC Microgrids are fundamentally changing the traditional power grid. Microgrid has revealed its promising potential as an active subsystem of the modern power grid. This paper reviews and analyses ways to boost and regulate the voltage of the AC-Micro-Grid-System(QBCIMGS) for improving the microgrid power quality. "A $Q B C($ Quadratic-boost-converter-inverter based AC-Micro-Grid-System(QBCIMGS) is conferred-here”. This work recommends-QBC(quadratic-boost-converter) between rectifier \&inverter. This paper investigates open loop and closed loop response of Quadratic boost-converter based AC-Micro-Grid-System(MGS) with Proportional resonant(PR) \& Hysteresis-controller $(\mathrm{HC})$. The mat lab outcome attained illustrates a developed dynamic-performance by using Hysteresiscontrolled AC-Micro-Grid-System(MGS).
\end{abstract}

Keywords - Photovoltaic (PV), Voltage Source Inverters (VSI), Pulse with Modulation (PWM), Quadratic Boost Converter $($ QBC), Sinusoidal Pulse Width Modulation (SPWM) proportional resonant $(P R) \&$ Hysteresis-controller $(H C)$.

\section{INTRODUCTION}

These days, sustainable power source frameworks, for example, energy unit stacks and photovoltaic power frameworks are getting to be a standout amongst the most alluring and promising wellsprings of giving electrical energy contrasted with the customary petroleum derivative energy producing sources. Sustainable power source frameworks offer monetary and natural points of interest in creating energy contrasted with the customary non-renewable energy source frameworks. Be that as it may, these sustainable power sources or frameworks have generally low voltage yield qualities and interest for high advance up DC-DC converter, for any potential commonsense application

The present pattern is centered around multi-string and module-situated innovation in medium and low power applications [1]. The photovoltaic-module arranged innovation is to introduce the framework with a basic mechanical gathering and is less demanding to interface with a lattice. The module arranged inverter is named single-stage, double-stage and multi-stage, considering the quantity of

power handling stages associated in course inside the inverter. An ongoing pressure distinguishes the double stage topologies with DC-DC stage and DC-AC stage as the most focused arrangement in module situated converter. Lattice associated sun powered micro-inverter essentially of two phases: first-stage working at high recurrence to venture up the board voltage upto $400 \mathrm{Vdc}$ and second stage working at network recurrence to change $\mathrm{dc}$ to ac and consequent association with the open utility.

These inverters are worked at the least power extend; their weight and volume are vulnerable of minimization in perspective on a mechanical combination in the rear of the equivalent-PV-board [2]. In this methodology, the initial step is either to limit or evacuate of the high recurrence transformer, which is a typical component in business micro-inverter. The second step is to characterize the most extreme DC increase required by the step-up voltage converter. Finally potential converter without galvanic disconnection that could take care of the voltage venture up issue. Subsequently a QBC has an aggressive transformer-less structure to take care of the issue of step-up information voltage ranges from $20 \mathrm{Vdc}-30 \mathrm{Vdc}$ up to 400Vdc[2].

Global-warming and the consumption of non-renewable energy sources are the real issues looked by each nation in this world. These issues have compromising results. The world is very nearly a bigger cataclysm. These issues can be diminished by moving the techniques for creating capacity to an alternate strategy. High effectiveness Quadratic Boost Converter was given by Saffar."Another-delicate-switched-(pulse-width-modulation) PWM-QBC(quadratic-boost-converter) which is reasonable for applications with a wide fluctuating DC-input-voltage, e.g. photovoltaic \&power-devices-systems"[3]-[4].

'Effectiveness-examination of QBC in CCM' was given by Navamani \&also presents 'proficiency-correlation of QBC in-continuous-conduction-mode(-CCM) \&discontinuous-conduction-mode(-DCM)'.

Analytical-expression for the DC segment and RMS segment of flows in CCM and DCM is inferred. 'Entire-misfortunes acquired in $\mathrm{QBC}$ ' were determined. 'DCM in three-cases' were talked about [5].

Examination and investigation of buck\& Quadratic Boost Converter was displayed by Nayak. The parameters of the
Revised Version Manuscript Received on 10, September 2019.

K.Saravanan, Department of EEE, SRM IST, Chennai, Tamil Nadu, , India (Email: saravanank96@gmail.com)

L.Porchelvi,, Department of EEE, SRM IST, Chennai, Tamil Nadu, India.(Email: porch.skj@gmail.com)

K. Selvakumar Department of EEE, SRM IST, Chennai, Tamil Nadu, India.(Email: selvakse@gmail.com) 


\section{HYSTERESIS CONTROLLED QUADRATIC BOOST CONVERTER BASED AC MICRO GRID SYSTEM WITH IMPROVED DYNAMIC RESPONSE}

converters were discovered with a thought of per unit ripple amount of inductor current and capacitor voltage. Voltage gain is similar in QBC\&CBC, but the power-stress-rating of the switch in earlier-one is more contrasted with the later [6]. "Assessment of Sic-MOSFET based QBC for PV-applications" was recommended by priya [7].

Plan methodology for limiting conduction misfortune for ZCT PWM-boost-converter was given by Hoon. The structure-framework to limit the conduction-misfortunes of the auxiliary-switch resounding way was proposed for a ZCT('Zero Currents Transition') PFC-boost-converter circuit. The soft-switching-technique diminishes switching misfortune at fundamental switch, however builds conduction misfortune at the auxiliary-switch-resonant-way because of the event of the resonant-current. The proposed plan method diminishes this issue. The detail task and circuit waveform in every mode are presented [8].

New control methodology for a Quadratic Boost Converter utilized in sun oriented energy framework was recommended by Mehdi [9]. The proposed control methodology depends on Lyapunov hypothesis that gives the strength of the converter considered as a switched relative framework. The voltage is settled at a steady esteem VMPP if the illumination shifts in a little interim, or the subordinate of the power regarding the voltage is settled at-zero. The framework doesn't contain any (-maximum-power-point-tracking)MPPT controller, the MPPT is incorporated in the control-procedure.

Sunlight based PV frameworks are increasing expanded consideration of academician, analysts, researchers and industrialist because of diminished expense of the sun-powered PV-material \&amp; contamination free generation of the energy[6]. "A-sun oriented-PV array encouraged single induction motor drive utilizing PWM-inverter-control" was utilized [10].

\section{PROPOSED DESIGN AND ANALYSIS - QBC BASED-MICRO-GRID-SYSTEM}

The exceeding literature does not deal with comparison of closed loop QBCIMGS (quadratic boost converter and inverter micro grid system) with PR controller and closed loop QBCIMGS with Hysteresis controller. Hence, the present effort deals with comparison of closed loop QBCIMGS (quadratic boost converter and inverter micro grid system) with PR controller and closed loop QBCIMGS with Hysteresis controller.

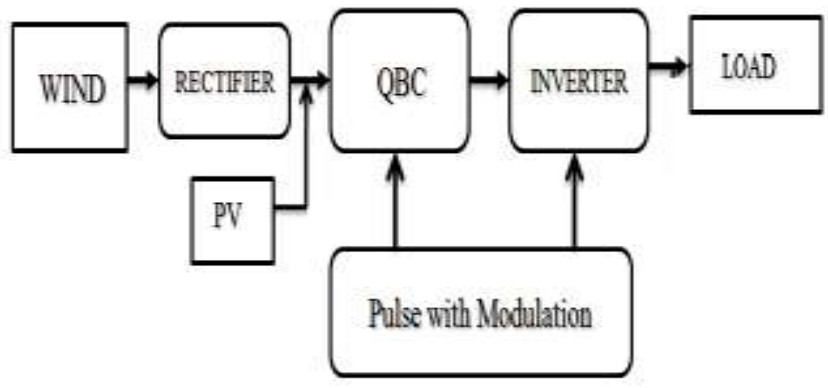

Figure 1. Block-Diagram of open loop QBCIMGS

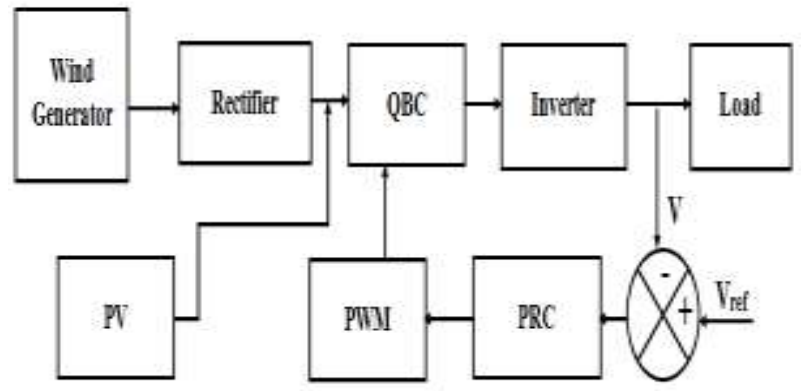

Figure 2. Block diagram of closed loop QBCIMGS with PR controller

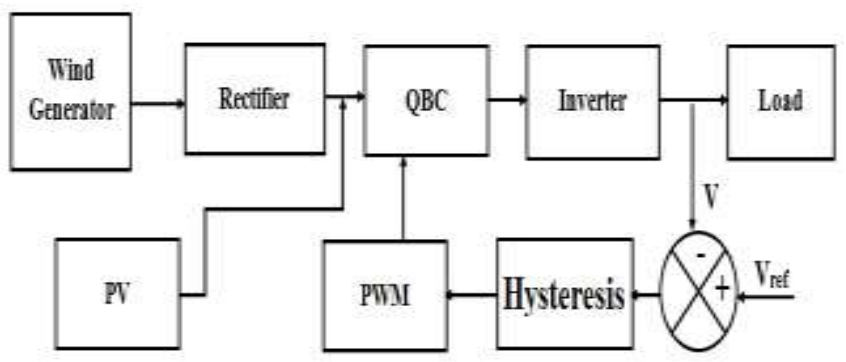

Figure 3. Block diagram of closed loop QBCIMGS with Hysteresis controller

The important-Voltage-Current-relative for the inductor $\mathrm{S}$ is,

$$
\begin{aligned}
& \mathrm{i}=\frac{1}{S} \int_{0}^{t} V d r+i_{0} \\
& V=S \frac{d i}{d r} \ldots \ldots \ldots . . .
\end{aligned}
$$

or

When the 'switch is turned on',

$$
\Delta i=\frac{\left(V_{\text {in }}-V_{\text {Trans }}\right) T_{o n}}{S}
$$

When the 'switch is turned off',

$$
\Delta i=\frac{\left(V_{\text {out }}-V_{\text {in }}+V_{D}\right) T_{\text {off }}}{S}
$$

By equating the $\Delta i$, we-can explain the $\mathrm{V}_{\text {out }}$

$$
V_{\text {out }}=\frac{\left(V_{\text {in }}-V_{\text {Trans }} \delta\right)}{(1-\delta)}-V_{D}
$$

Ignoring the voltage-drop across diode $V_{D}$ and transistor $V_{\text {Trans, }}$

$$
V_{\text {out }}=\frac{\left(V_{\text {in }}\right)}{(1-\delta)}
$$

Duty-ratio $(\delta)$ is assorted to boost-the yield-voltage is desired-value.

\section{SIMULATION RESULTS AND DISCUSSION}

Circuit diagram of open loop QBCIMGS (quadratic boost converter and inverter micro grid system) with disturbance is delineated in Fig.4. Voltage across PV is delineated in Fig.5 $\&$ its value increases from $40 \mathrm{~V}$ to $58 \mathrm{~V}$. Voltage Across wind is delineated in Fig. 6 \& its value is $60 \mathrm{~V}$. 


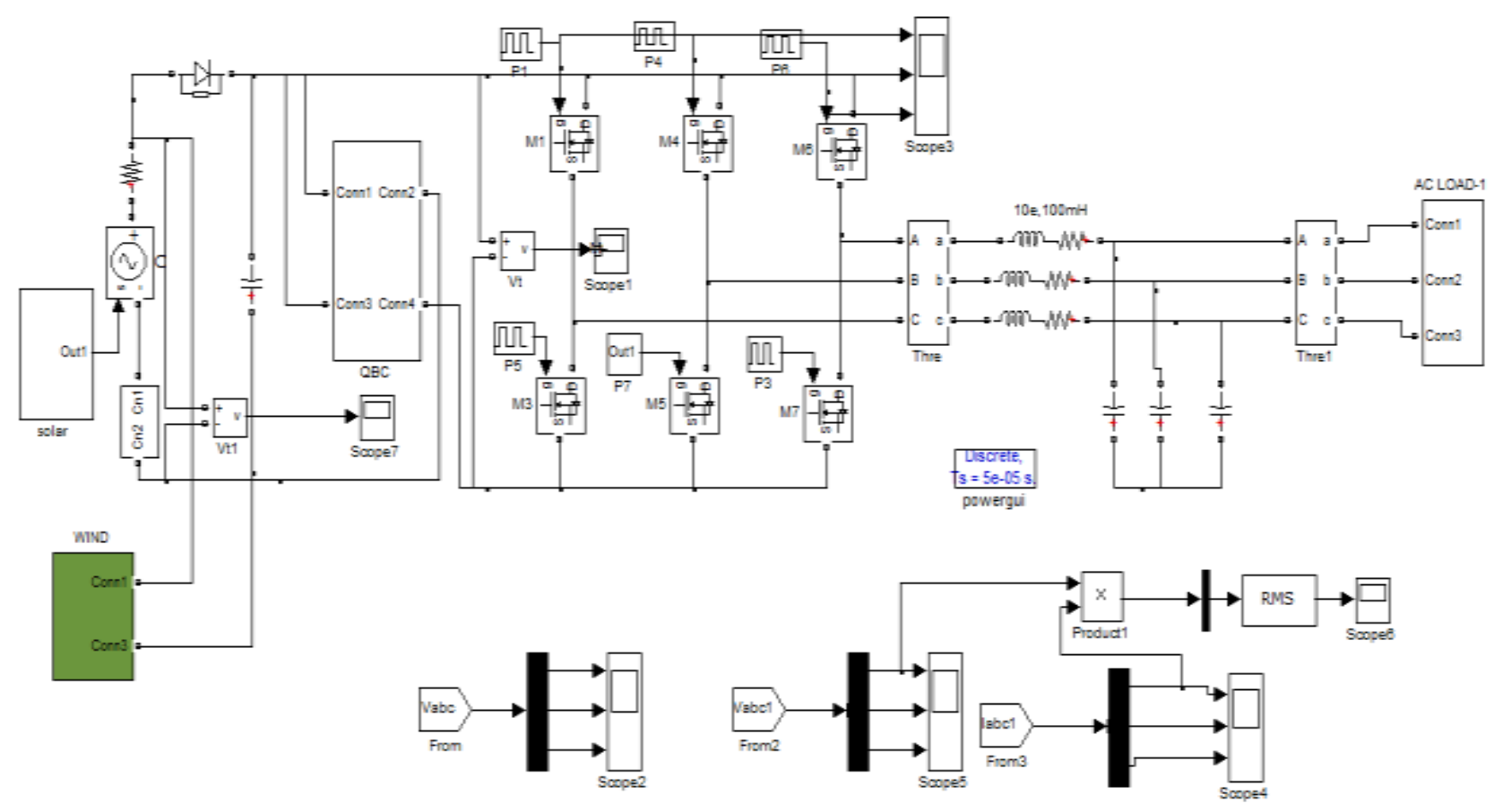

Figure 4 Circuit diagram of Open loop QBCIMGS with disturbance

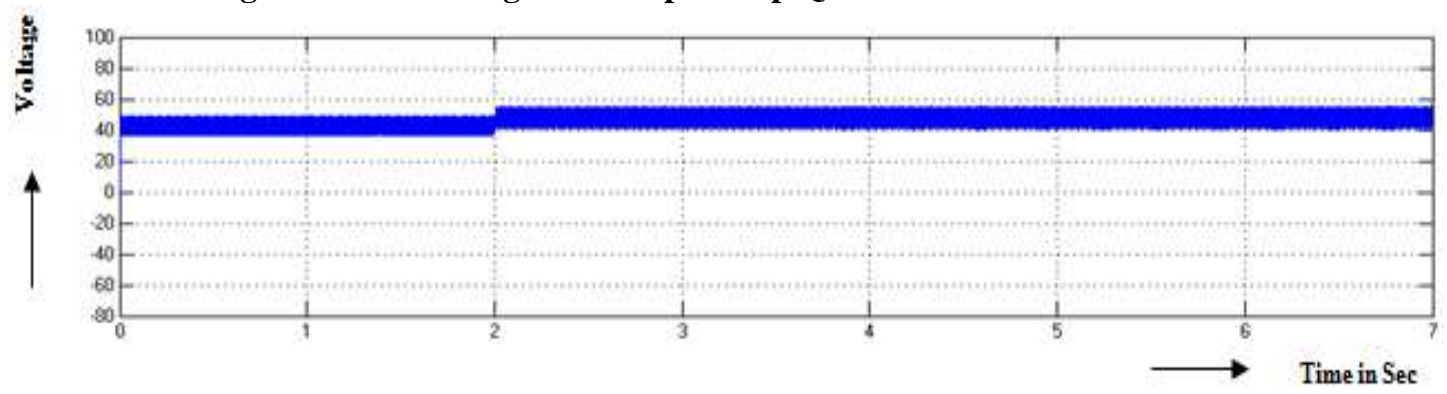

Figure 5 Voltage across PV
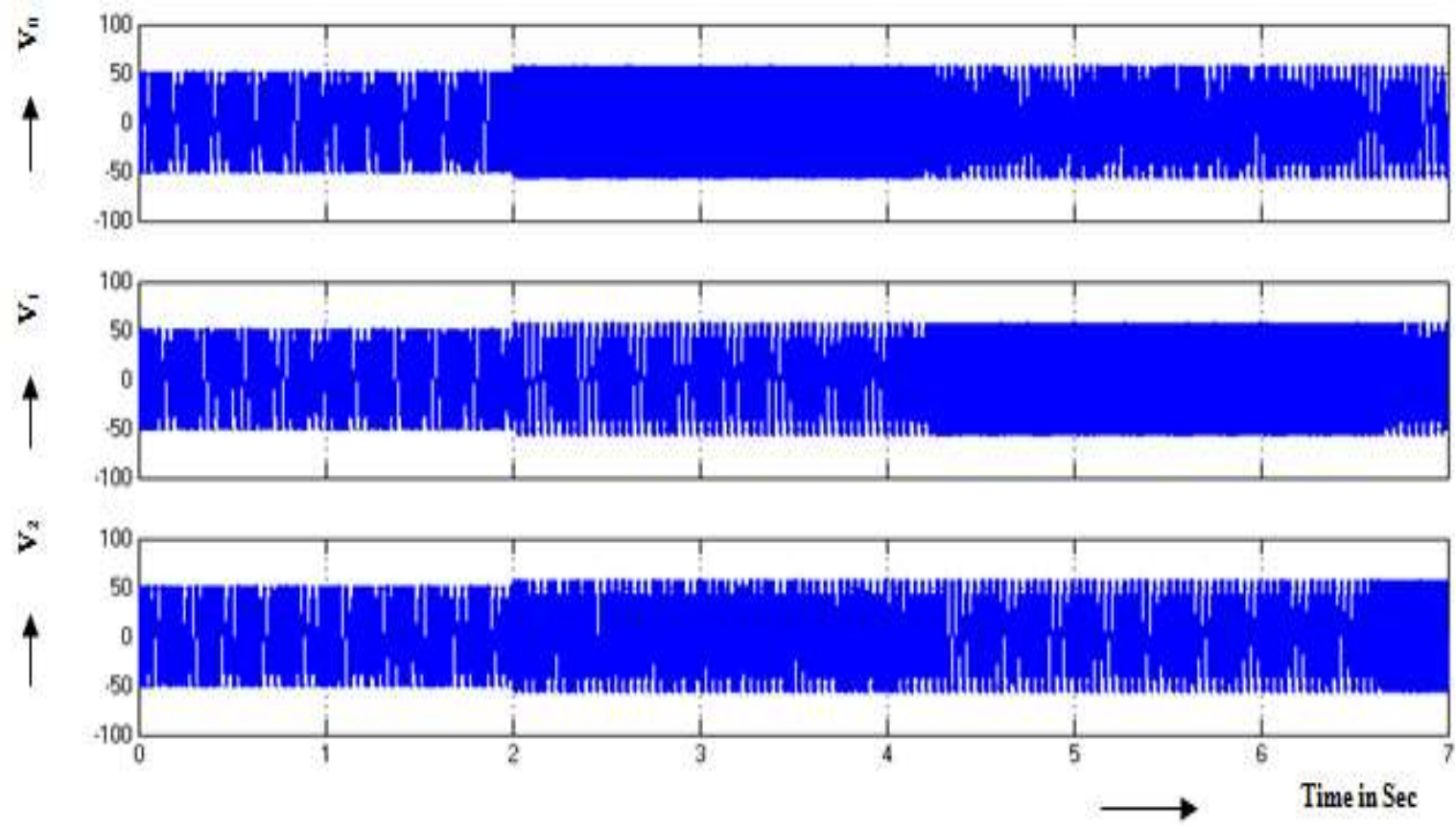

Figure 6. Voltage Across wind

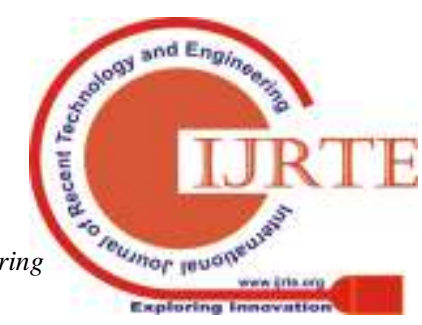




\section{HYSTERESIS CONTROLLED QUADRATIC BOOST CONVERTER BASED AC MICRO GRID SYSTEM WITH IMPROVED DYNAMIC RESPONSE}

Voltage across quadratic boost converter is delineated in Fig. $7 \&$ its value is 480 V. Output voltage across inverter RL -load is delineated in Fig. 8 \& its value is $400 \mathrm{~V}$. Output

current through RL load is delineated in Fig.9 \& its value is 3.8A. Output power is delineated in Fig. $10 \&$ its value is $820 \mathrm{~W}$.

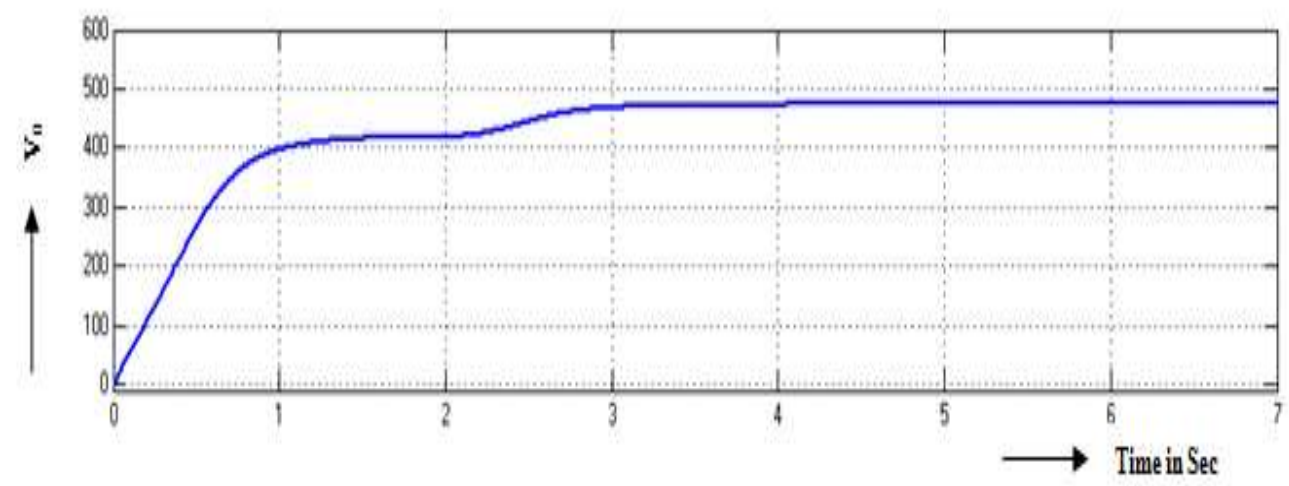

Figure 7. Voltage across quadratic boost converter
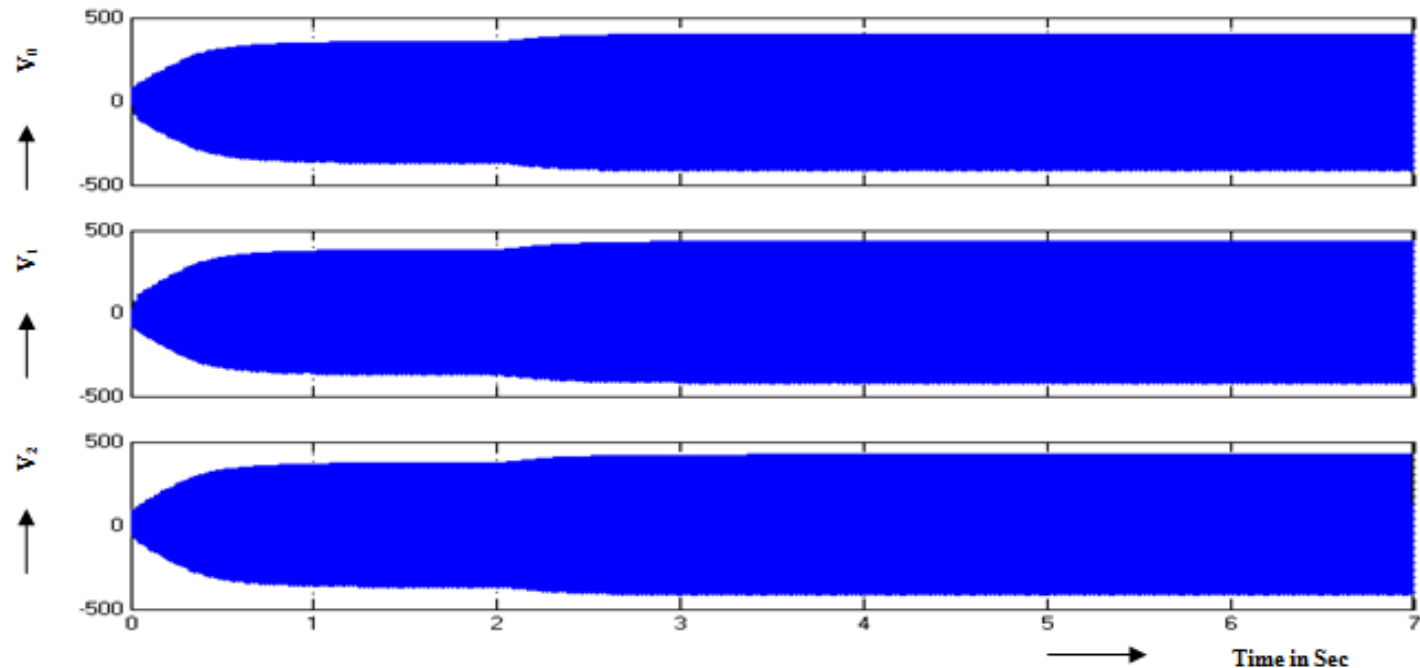

Figure 8. Output voltage of inverter with $\mathrm{RL}-$ load
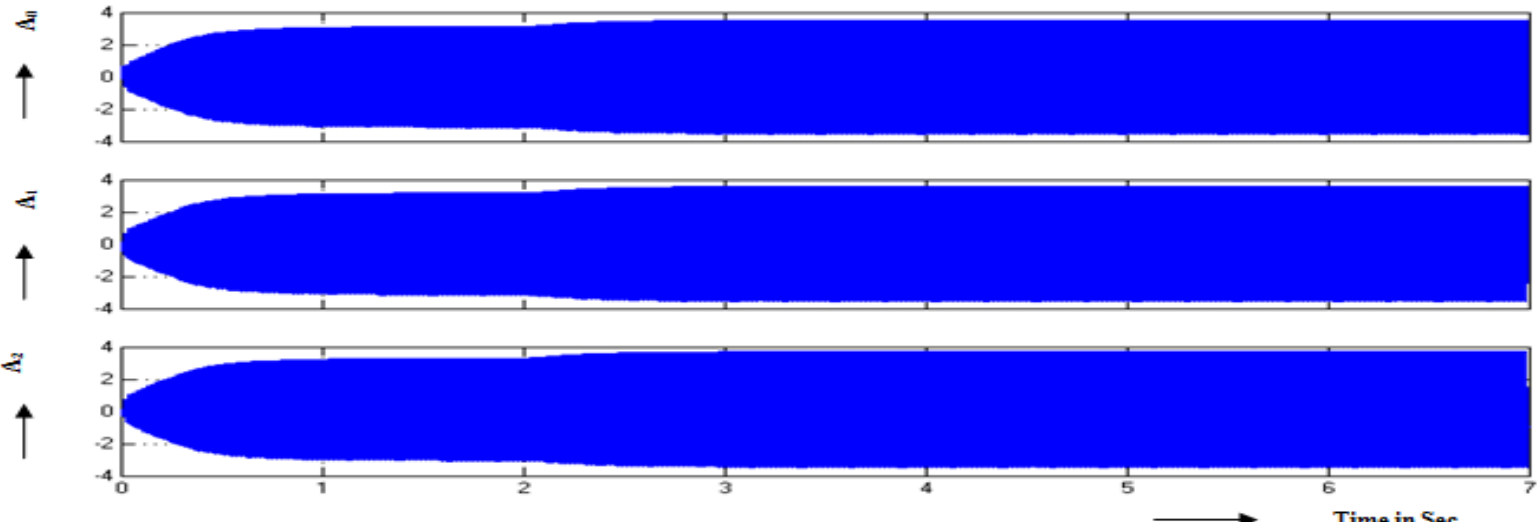

Figure 9. Current through RL load

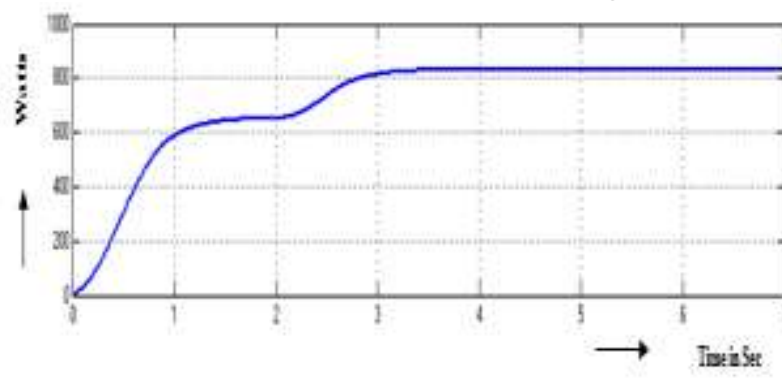

Figure 10. Output power

Circuit diagram of closed loop QBCIMGS (quadratic boost converter and inverter micro grid system) with PR controller is delineated in Fig.11. Voltage across PV is delineated in Fig. 12 \& its value increases from $40 \mathrm{~V}$ to $58 \mathrm{~V}$. Voltage Across wind is delineated in Fig.13 \& its value is $60 \mathrm{~V}$. Voltage across quadratic boost converter is delineated in Fig. 14 \& its value is $440 \mathrm{~V}$. Output voltage across inverter RL -load is delineated in Fig. 15 \& its value is $300 \mathrm{~V}$. Output current through RL load is delineated in Fig. 16 \& its value is 
3.4A. Output power is delineated in Fig.17\&its value is $700 \mathrm{~W}$.

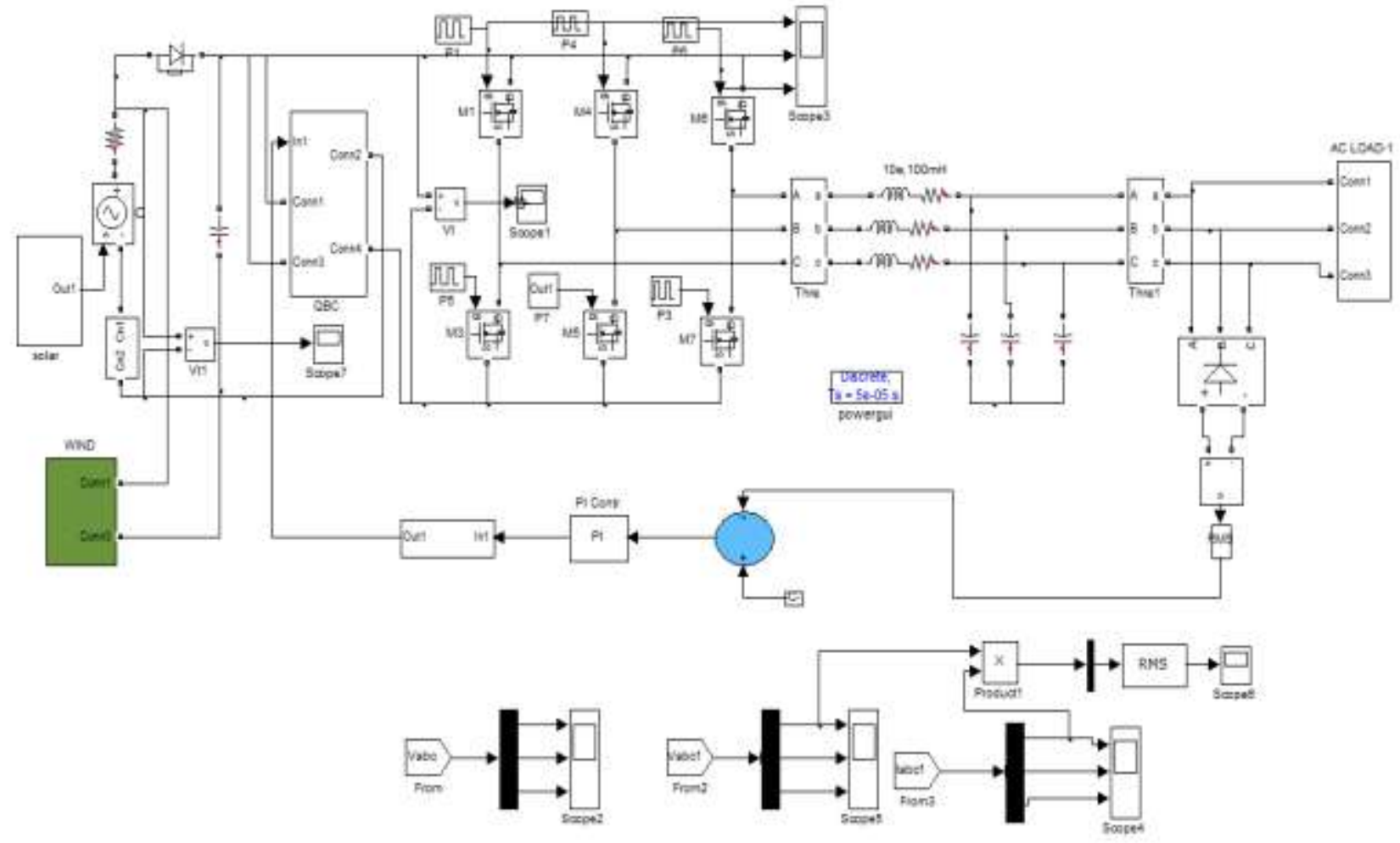

Figure 11. Circuit diagram of Closed loop QBCIMGS with PR controller

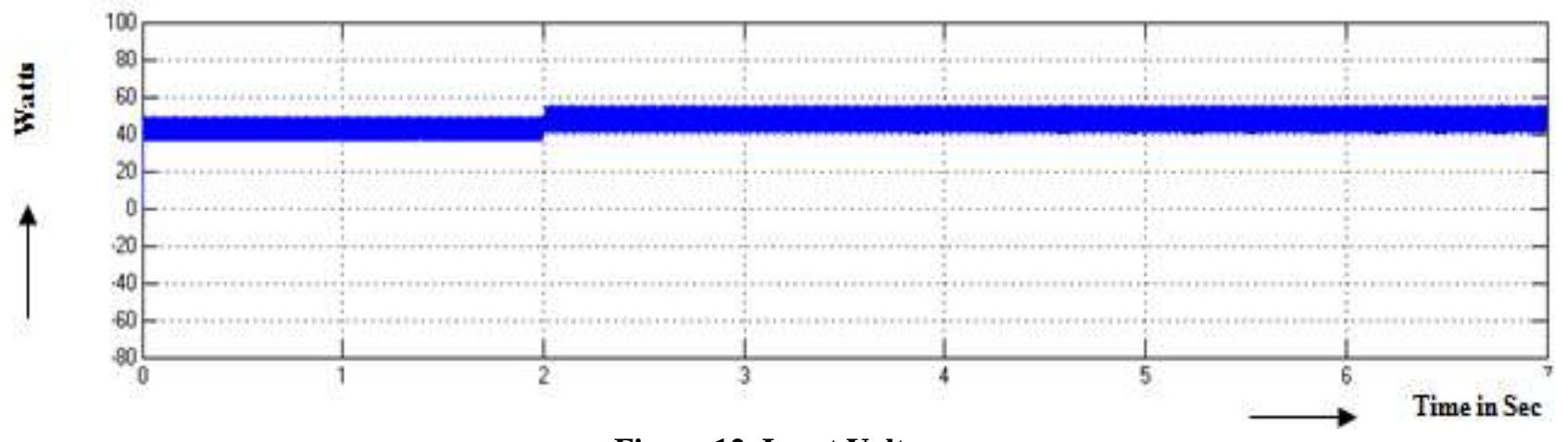

Figure 12. Input Voltage

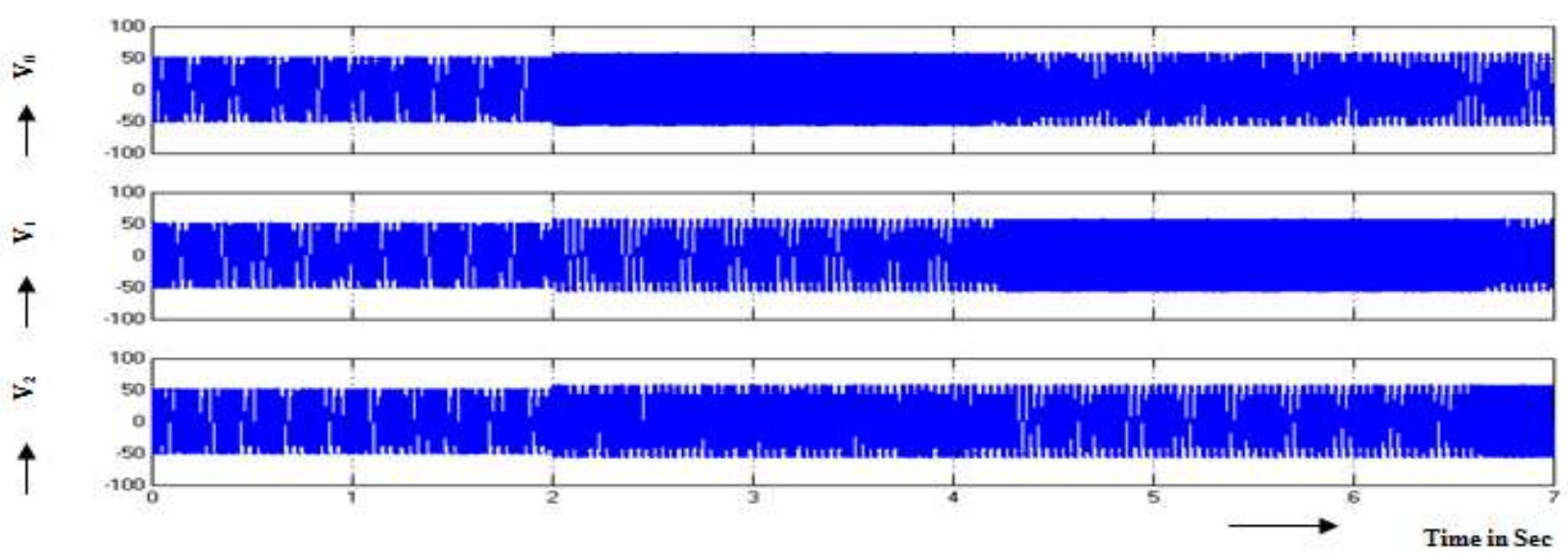

Figure 13. Voltage Across wind

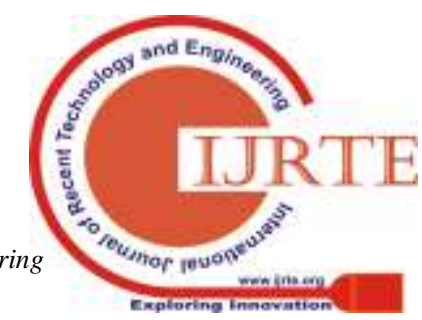




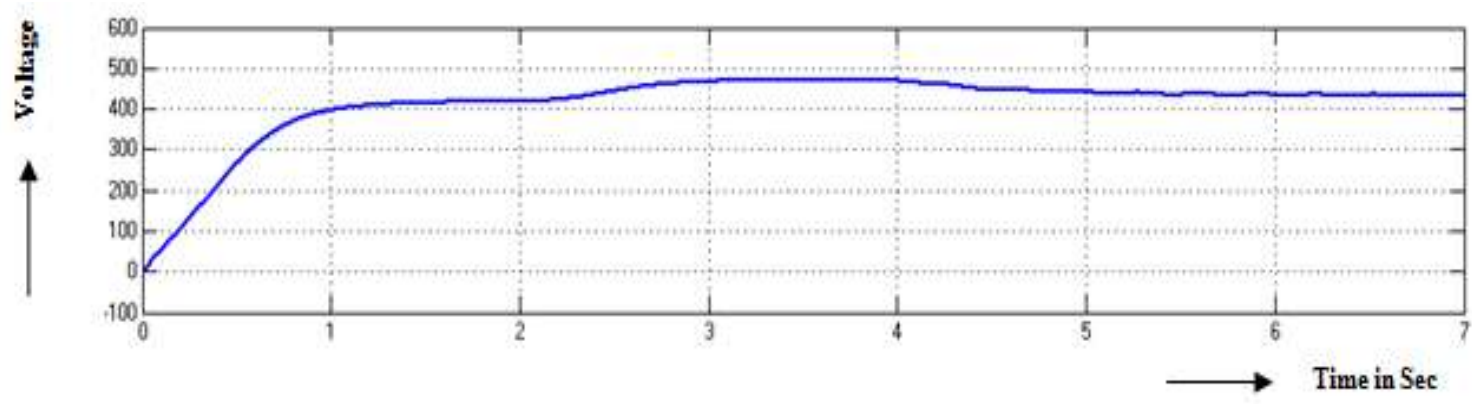

Figure 14. Voltage across quadratic boost converter

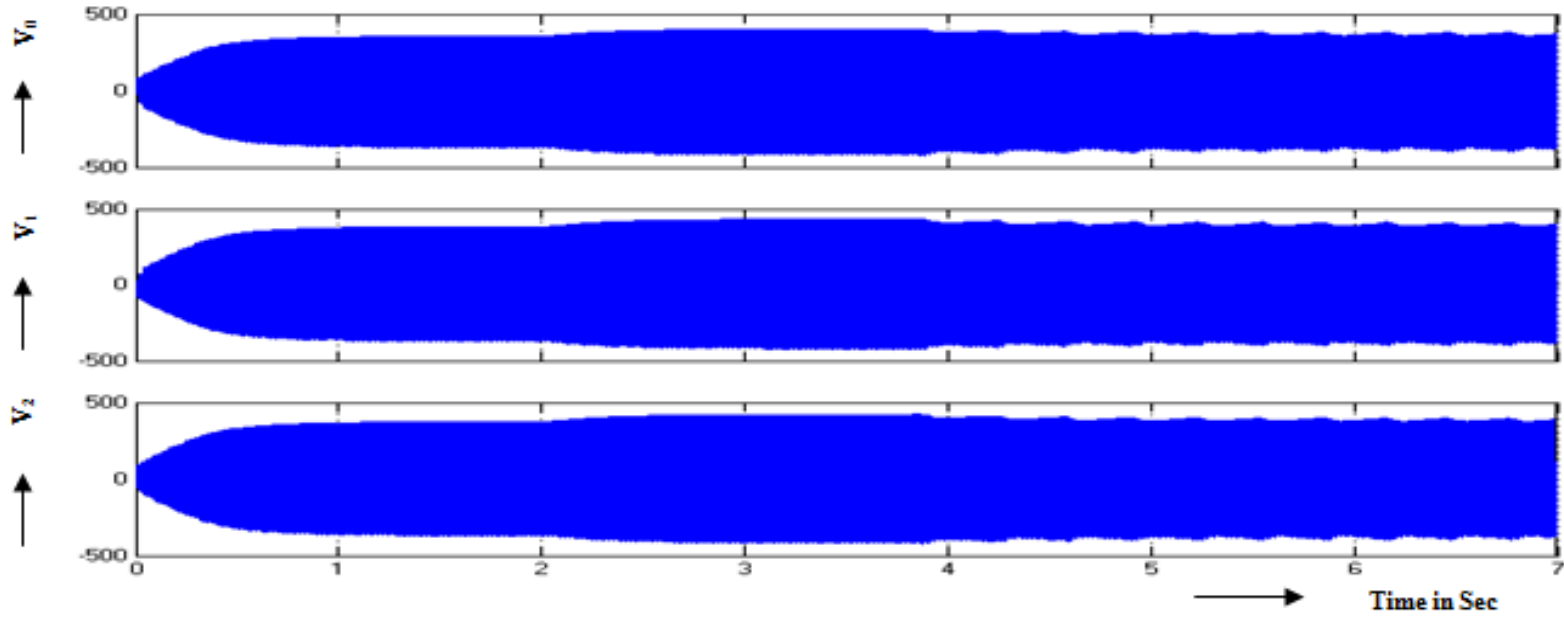

Figure 15. Output voltage of inverter with RL -load

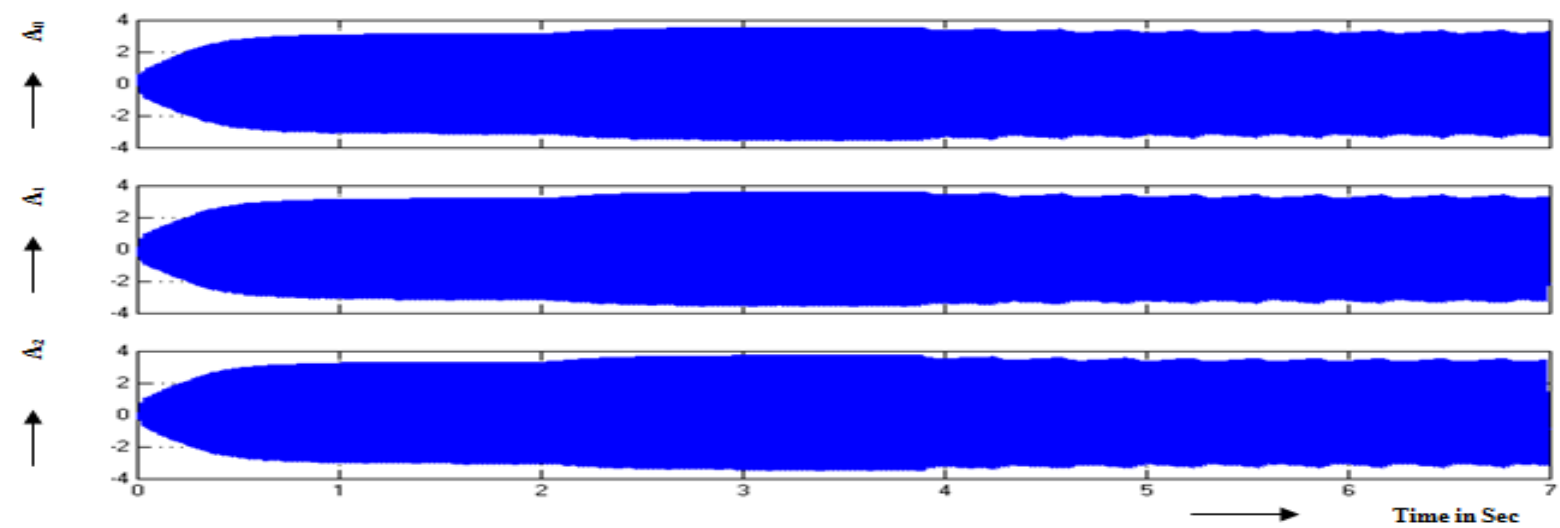

Figure 16. Current through RL load

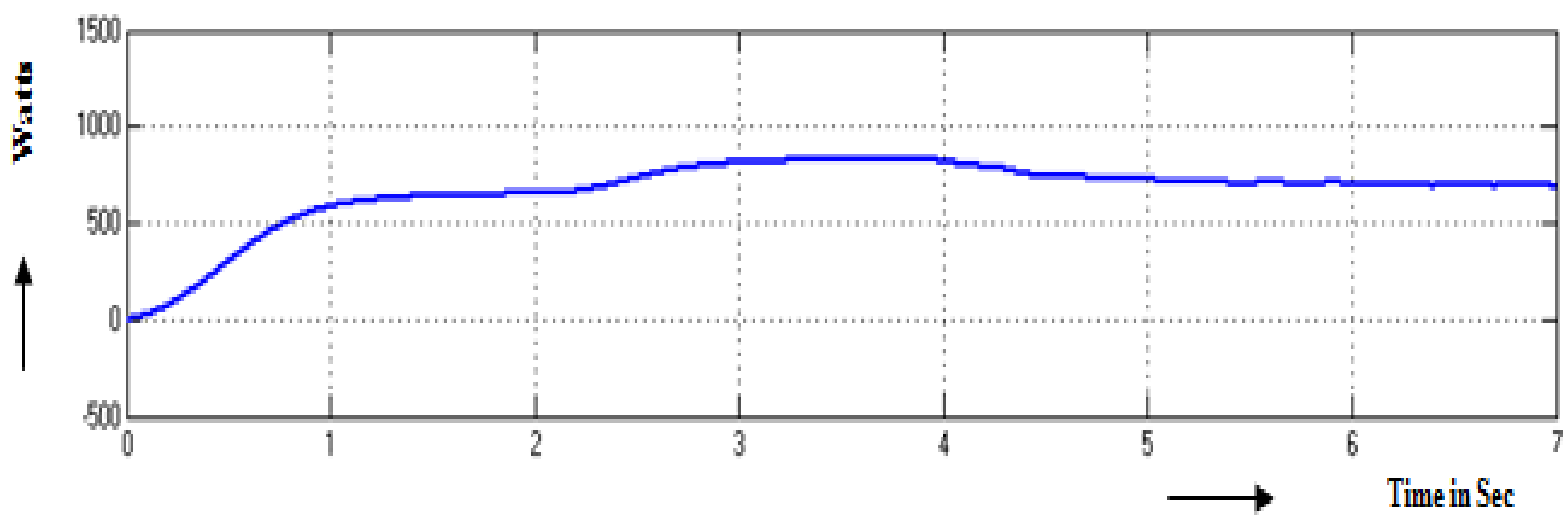

Figure 17. Output power

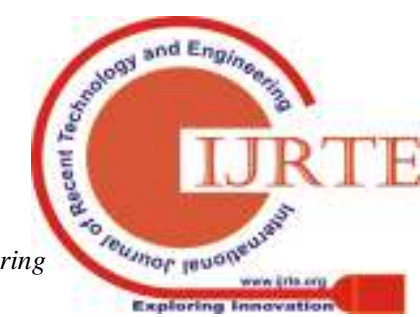


Circuit diagram of closed loop QBCIMGS(quadratic boost converter and inverter micro grid system) with Hysteresis

Voltage Across wind is delineated in Fig. 20 \& its value is $60 \mathrm{~V}$. Voltage across quadratic boost converter is delineated in Fig. $21 \&$ its value is $420 \mathrm{~V}$. Output voltage across inverter $\mathrm{RL}-$ load is delineated in Fig. 22 \& its value is $300 \mathrm{~V}$. Output controller is delineated in Fig.18. Voltage across PV is delineated in Fig. 19 \& its value increases from $40 \mathrm{~V}$ to $58 \mathrm{~V}$. current through RL load is delineated in Fig. 23 \& its value is 3.4A. Output power is delineated in Fig. $23 \&$ its value is 640W.

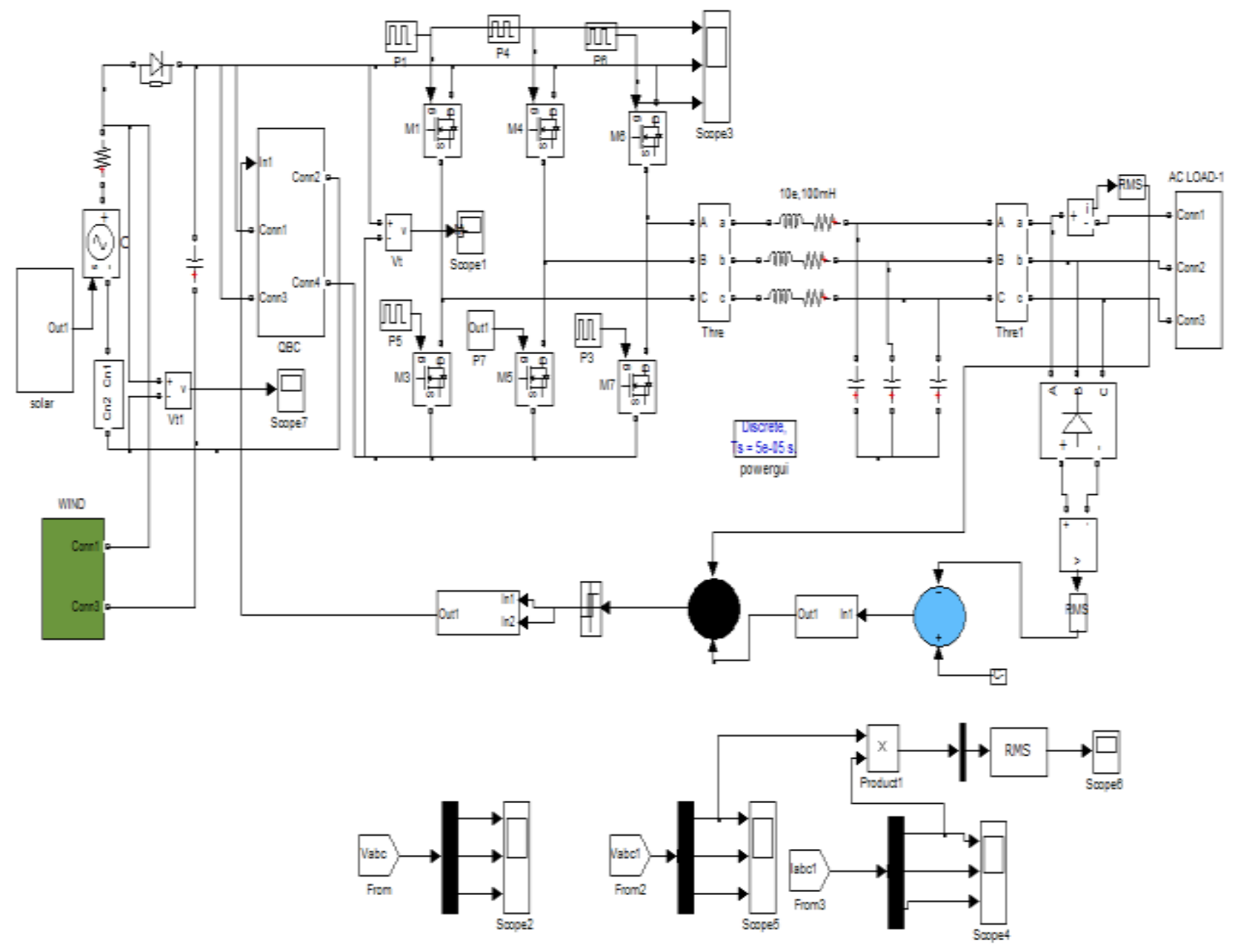

Figure 18. Circuit diagram of closed loop QBCIMGS with Hysteresis controller

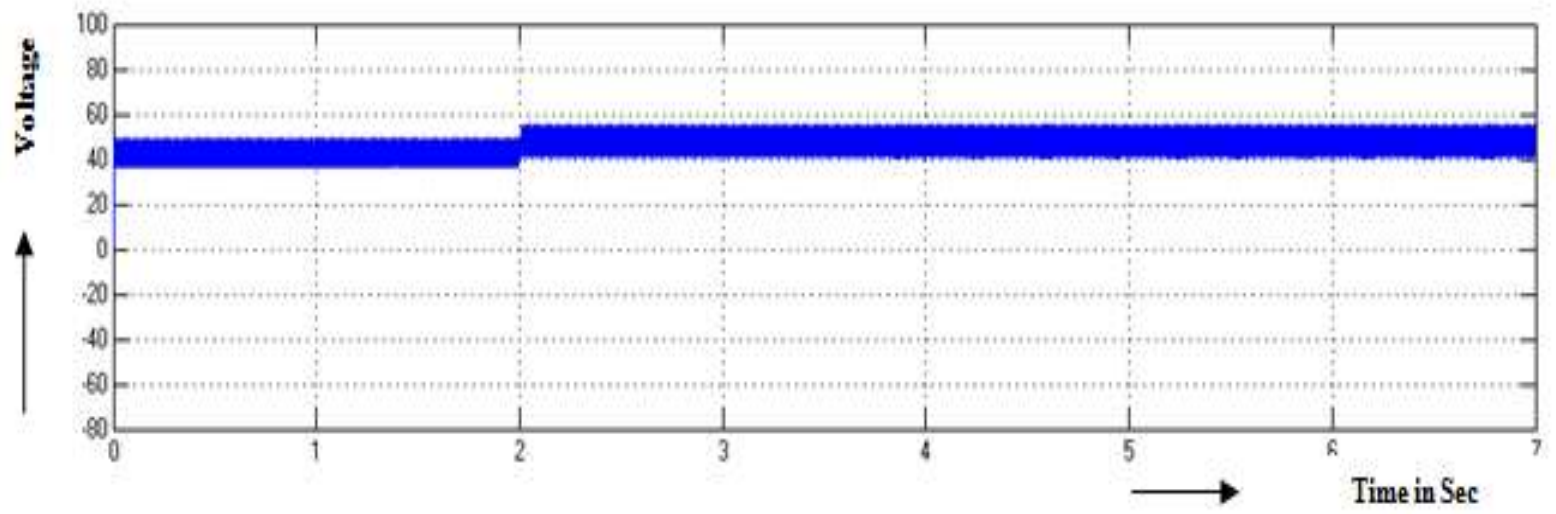

Figure 19. Voltage across $P V$ 


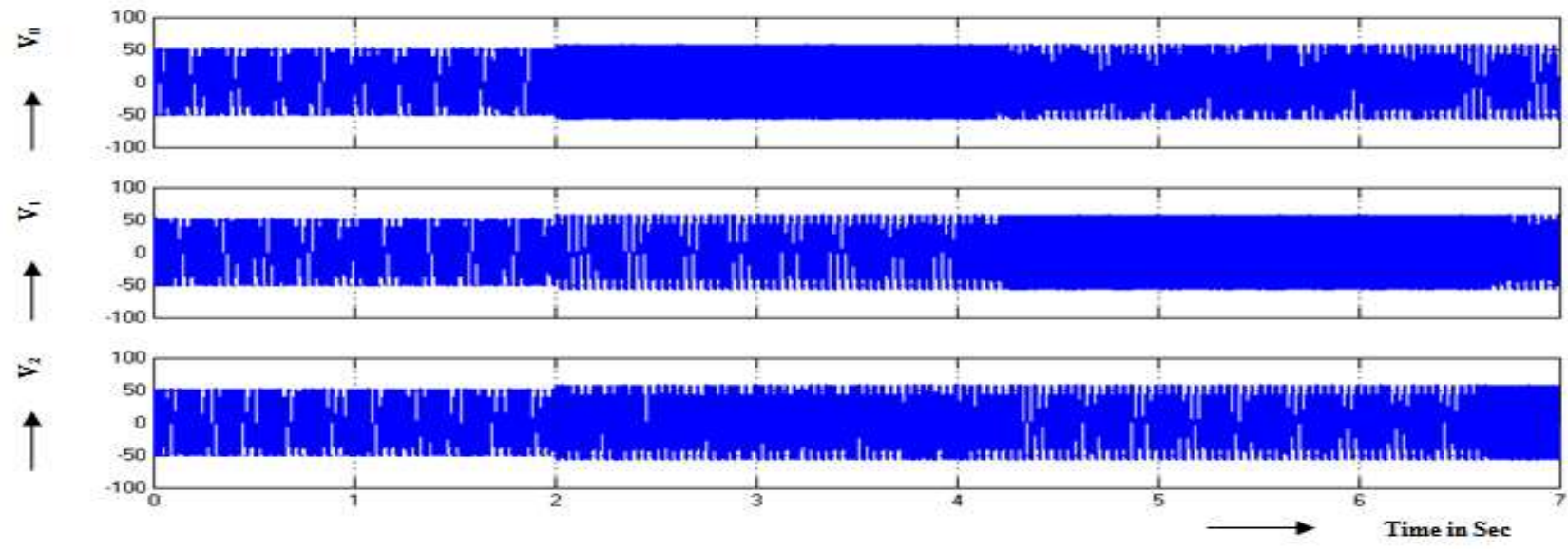

Figure 20. Voltage Across wind

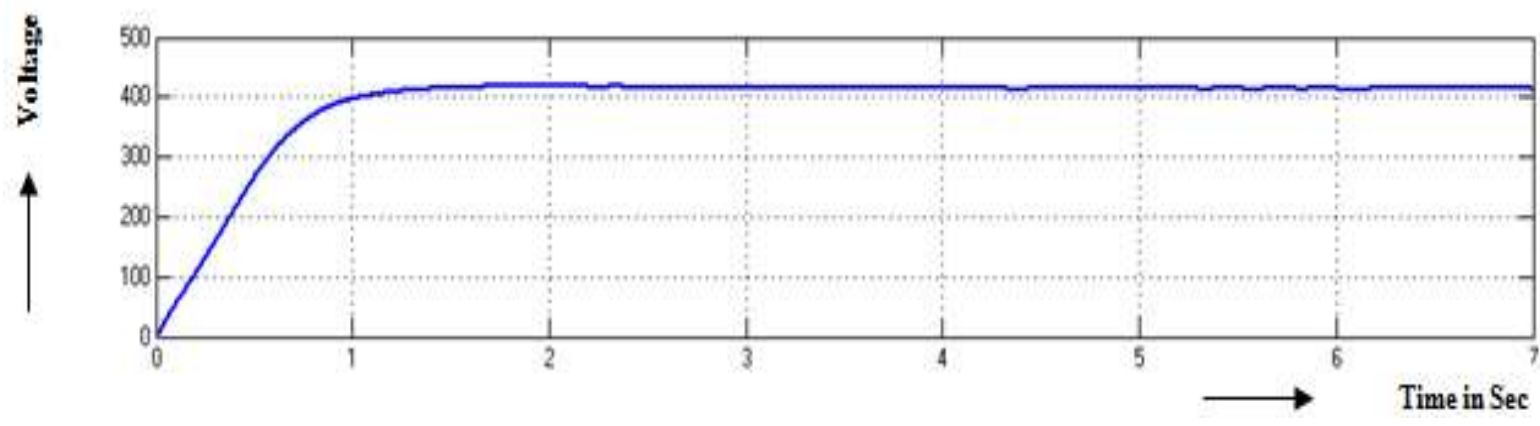

Figure 21. Voltage across quadratic boost converter

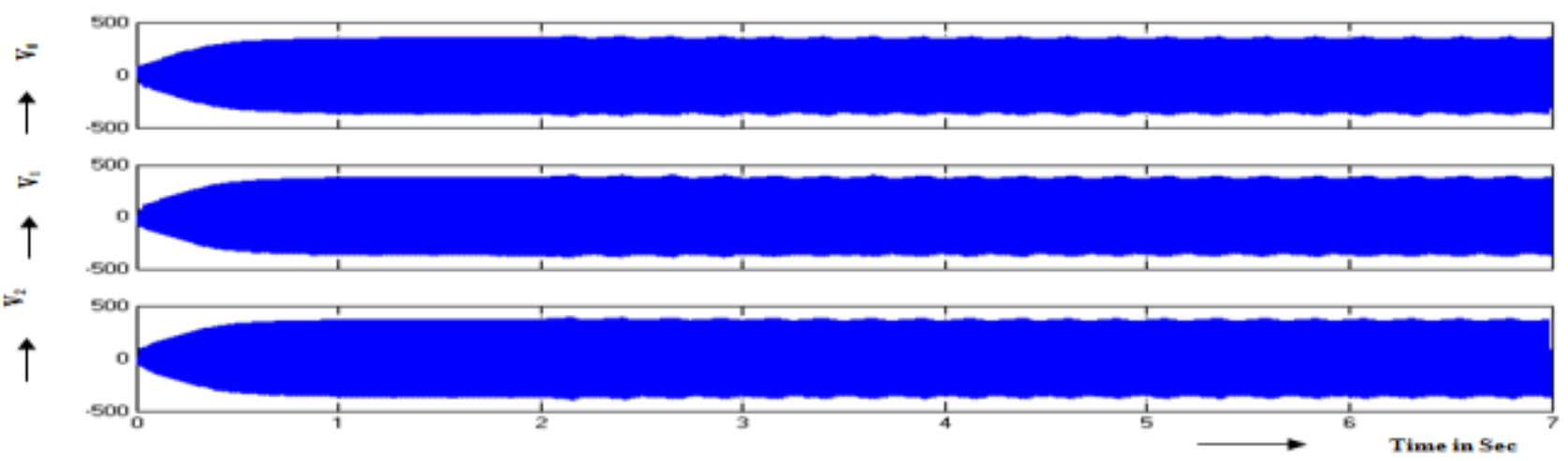

Fig 22. voltage Across inverter RL -load
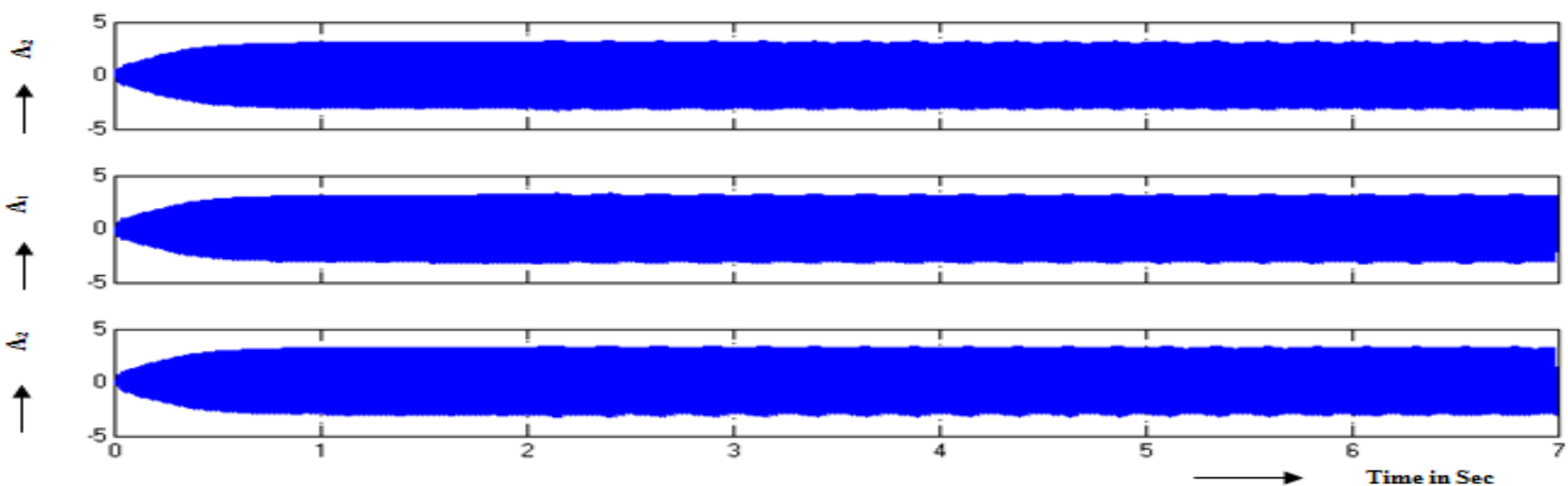

Figure 23. current through RL load

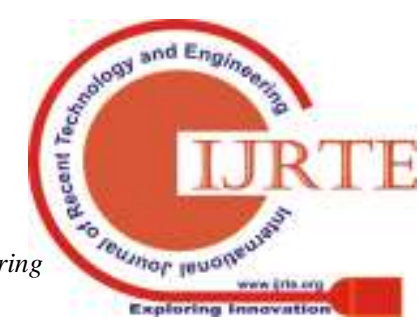




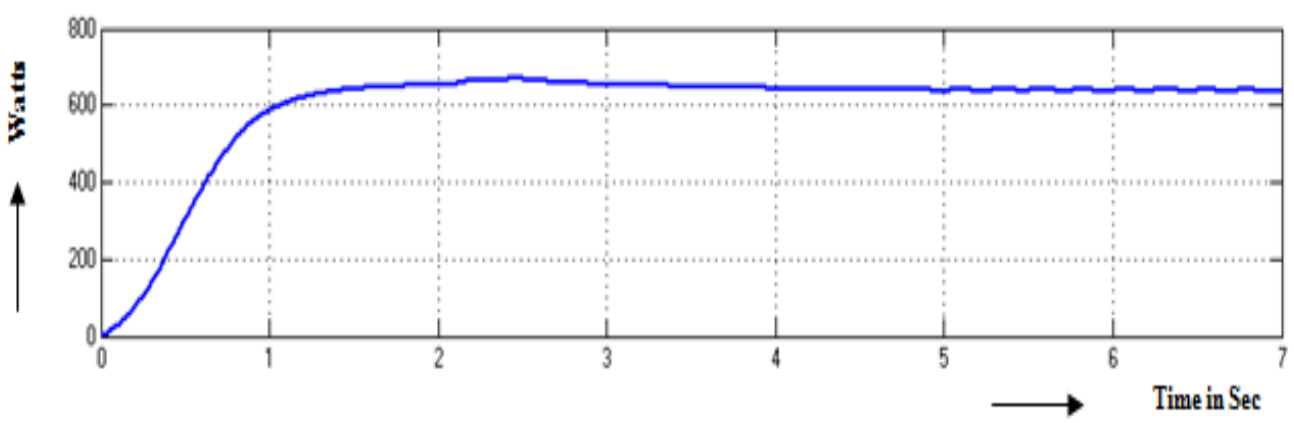

Figure 24. Output power

Comparison of Time Domain Parameters is given in Table-1. By using HC, the rise time is reduced from 2.2Sec to $2.1 \mathrm{Sec}$; settling time is reduced from $3.4 \mathrm{Sec}$ to $2.7 \mathrm{Sec}$; peak time is reduced from $3.1 \mathrm{Sec}$ to $2.5 \mathrm{Sec}$; Steady state error is reduced from $2.4 \mathrm{~V}$ to $1.7 \mathrm{~V}$.
TABLE-1 COMPARISON OF TIME DOMAIN PARAMETERS WITH PR AND HC

\begin{tabular}{|l|l|l|l|l|}
\hline Controller & $\mathrm{T}_{\mathrm{r}(\mathrm{Sec})}$ & $\mathrm{T}_{\mathrm{s}(\mathrm{Sec})}$ & $\mathrm{T}_{\mathrm{p}(\mathrm{Sec})}$ & $\mathrm{E}_{\mathrm{ss}(\mathrm{V})}$ \\
\hline $\mathrm{PR}$ & 2.2 & 3.4 & 3.1 & 2.4 \\
\hline $\mathrm{HC}$ & 2.1 & 2.7 & 2.5 & 1.7 \\
\hline
\end{tabular}

\section{EXPERIMENTAL RESULTS}

QBC with Three Phase Inverter Hardware Diagram is as appeared in Fig 25.

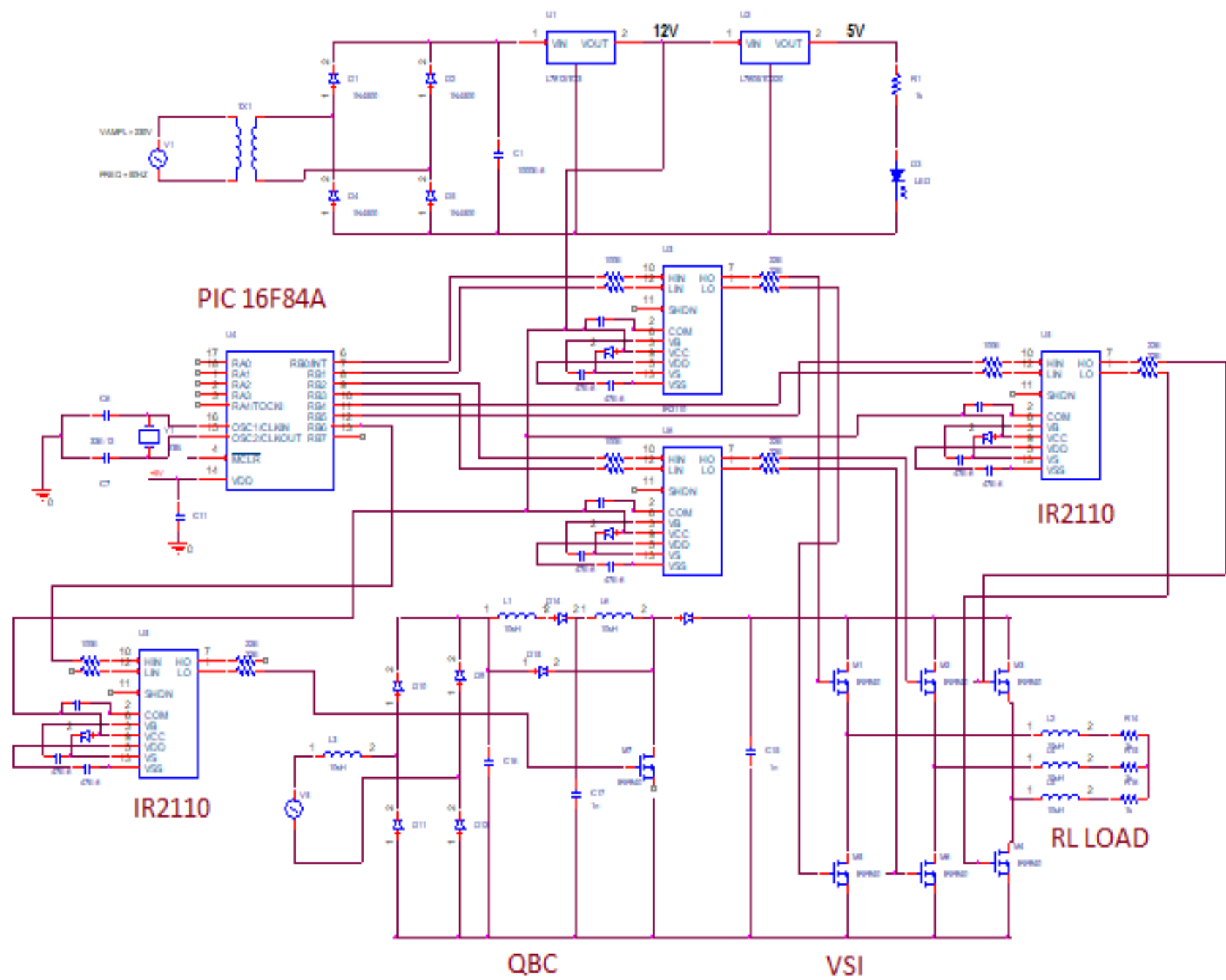

Figure 25. QBC with Three Phase Inverter Hardware Diagram 


\section{HYSTERESIS CONTROLLED QUADRATIC BOOST CONVERTER BASED AC MICRO GRID SYSTEM WITH IMPROVED DYNAMIC RESPONSE}

Hardware snap short is appeared in Fig 26.

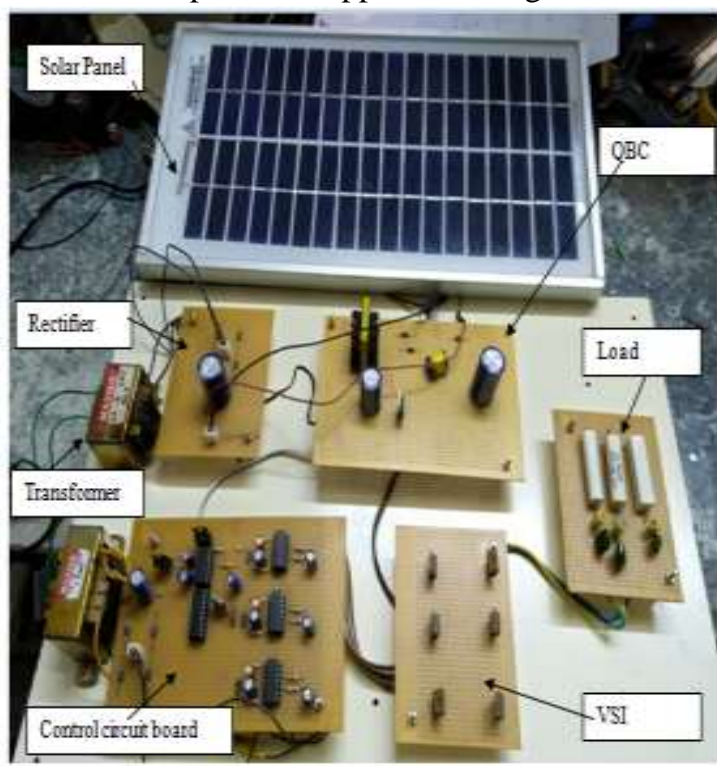

Figure 26. Hardware snap shot

Input voltage, Voltage across PV, Switching pulse for QBC S1, Voltage across QBC, Switching pulse for inverter M1, Switching pulse for inverter M3, Switching pulse for inverter M5, Voltage across line to neutral and Voltage across line to line are appeared in Fig $27,28,29,30,31,32,33,34,35$ respectively.

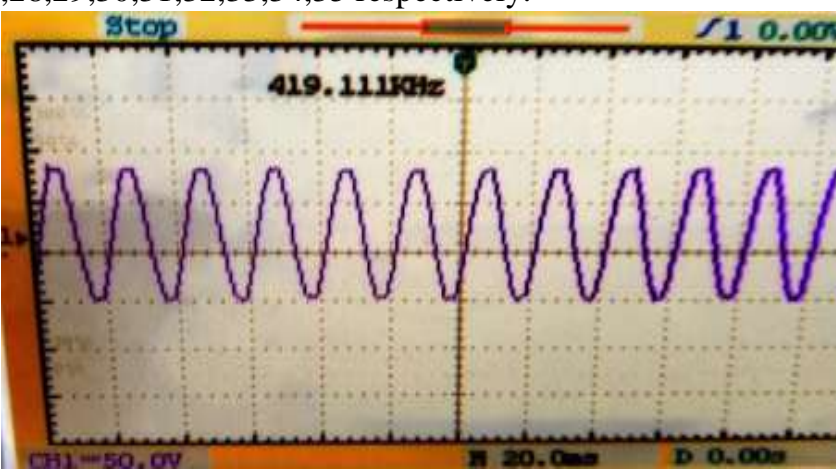

Figure 27. Input voltage

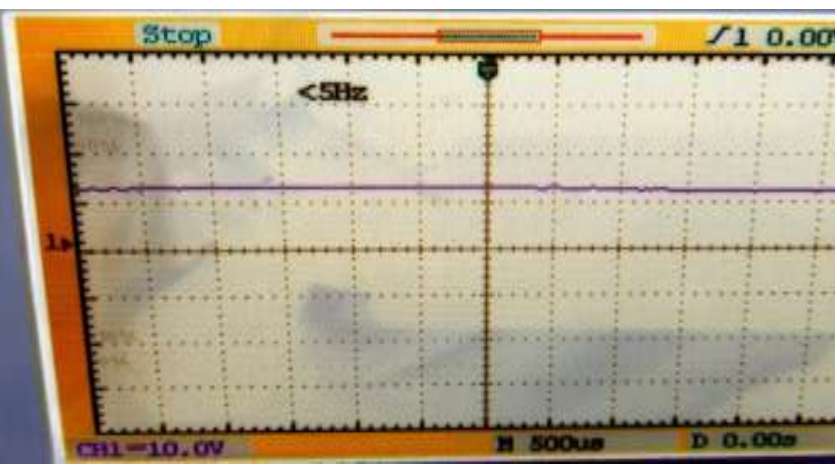

Figure 28. Voltage across PV

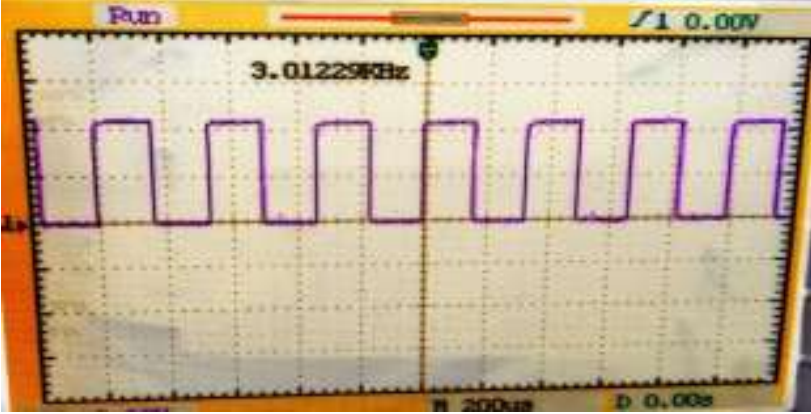

Figure 29. Switching pulse for QBC S1

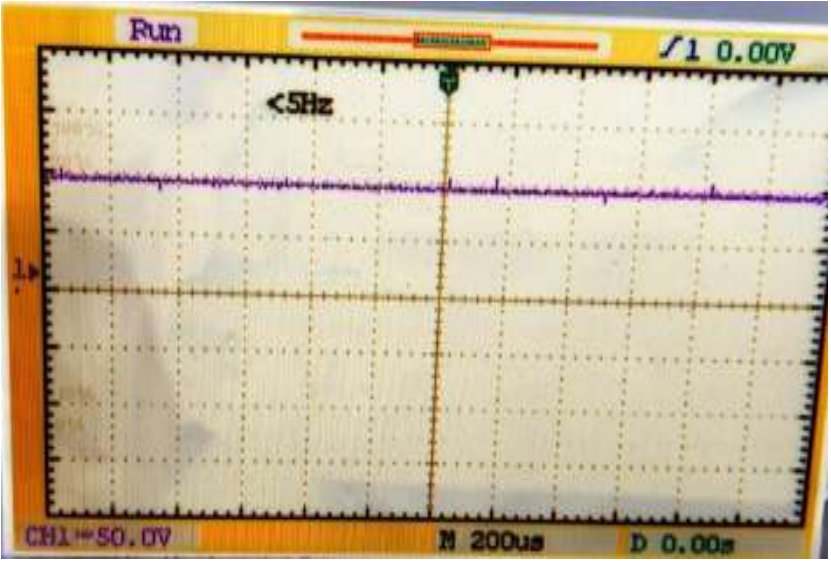

Figure 30. Voltage across QBC

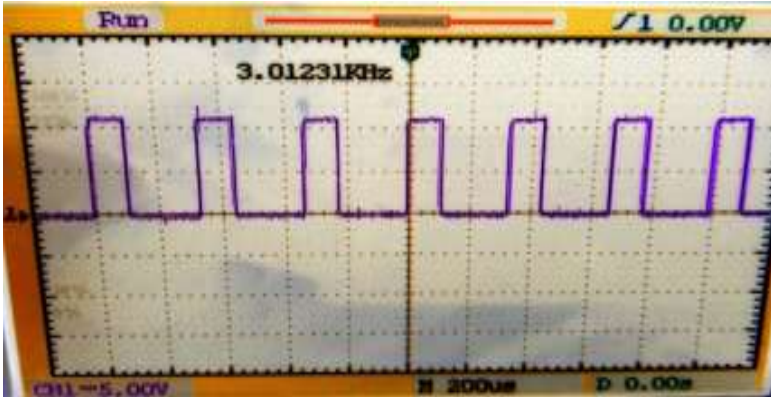

Figure 31. Switching pulse for inverter M1

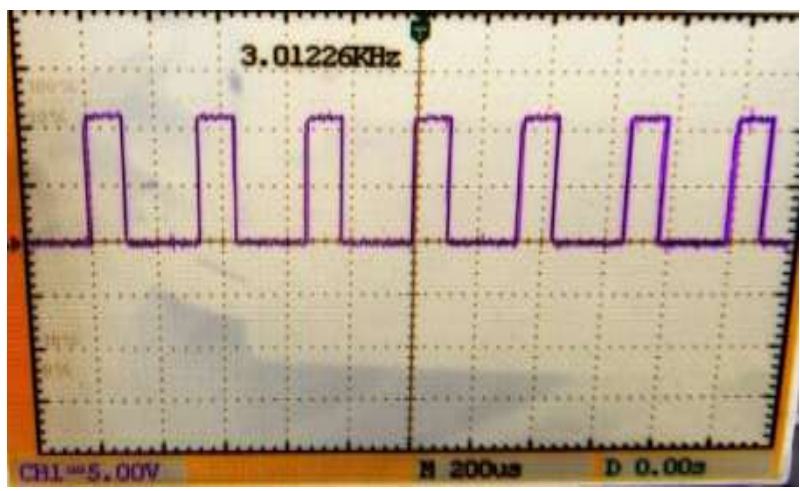

Figure 32 Switching pulse for inverter M3

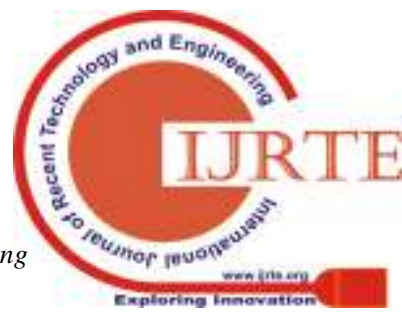




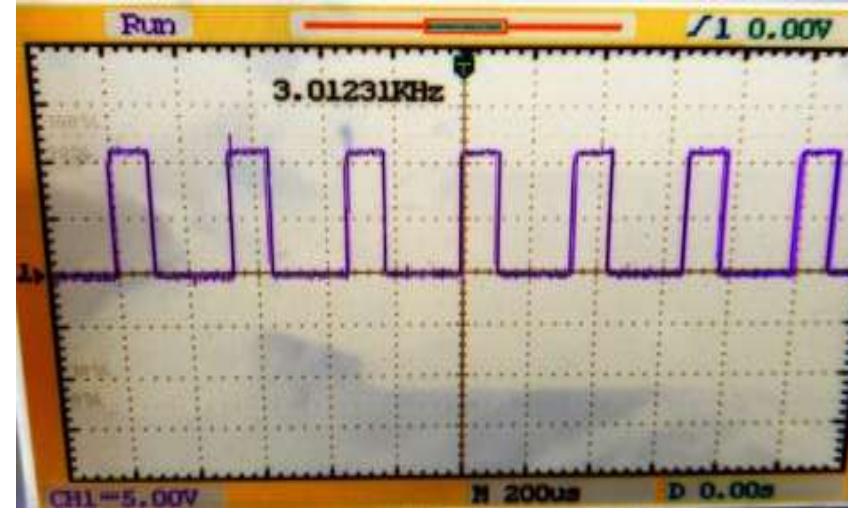

Figure 33 Switching pulse for inverter M5

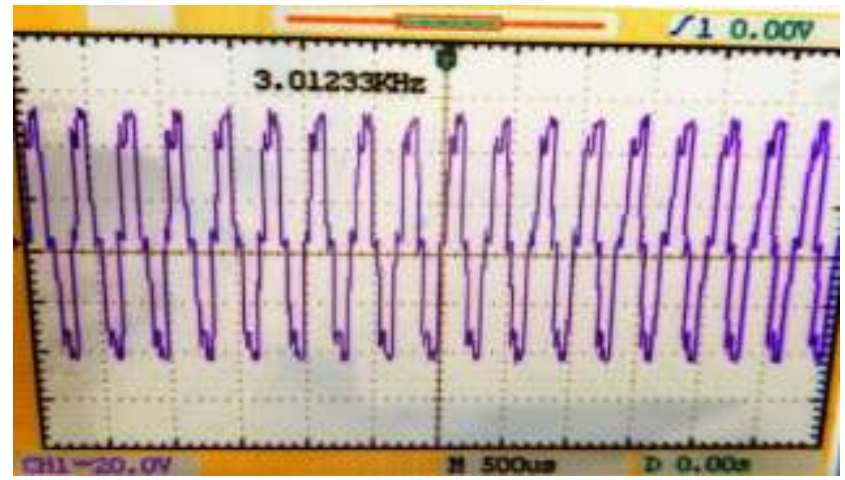

Figure 34 Voltage across line to neutral

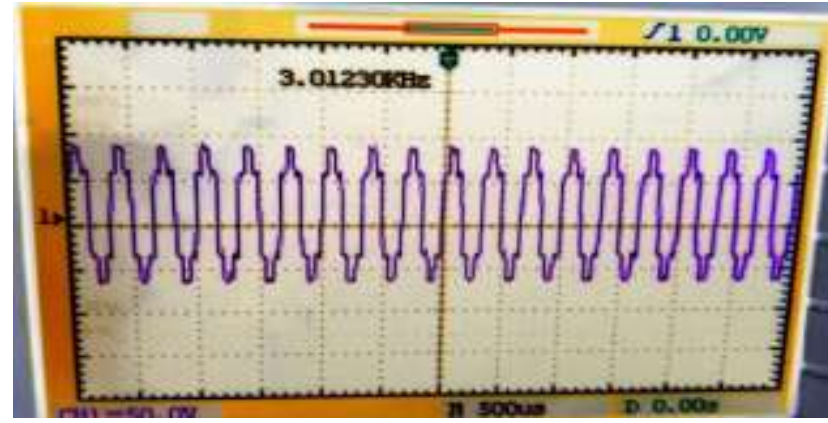

Figure 35. Voltage across line to line

\section{CONCLUSION}

Closed loop QBCIMGS (quadratic boost converter and inverter micro grid system) with Proportional resonant and Hysteresis controller are modeled and simulated using Mat lab Simulink. The simulation-outcomes of 'closed-loop-system with-HC\&-PR' are presented. The '-settling-time' is diminished to $2.7 \mathrm{Sec}$ and '-steady-state -error' is diminished to $1.7 \mathrm{~V}$ by using Hysteresis-controller. Thus the response of HC-controlled system is superior-to the-PR-controlled-system.. The benefits of-proposed-system are little harmonic-content and fast response. The drawback of Quadratic-boost-converter is that-it is appropriate for low power

\section{REFERENCES}

1. O.Lopez-Santos, -L.Martinez-Salamero, -G.Garcia, -H.Valderrama- Blavi. "-Sliding-mode control-of-a-transformer-less-dual-stage-gridconnected-p hotovoltaic-micro-inverter”. -2013-10th International -Multi-Conference-on-Systems,-Signals \&-Devices (SSD)-Hammamet,-Tunisia, March 18-21, 2013.

2. O.Lopez-Santos, -L.Martinez-Salamero, -G.Garcia,
-H.Valderrama- Blavi, $\quad$-D.Mercury. "-Efficiency-analysis-ofa-Sliding-mode-Controlled-Quad ratic-Boost-Converter".-IET-Power -Electronics.-2013.

3. Al-SaffarMA,-IsmailEH,-SabzaliAJ."-High-efficiency-Q BC(quadratic-boost-converter)". $\quad$-applied P.E..conf..,\&Exposition(AP-EC);-2012-feb.-pp-1245-52.

4. NewlinDJS,--RamalakshmiR,--RajasekaranS, “-A-perfor mance-comparison-of-interleaved-boost-converter\&-con ventional-boost-converter-for-renewable-energy-applicati on".-International-Conf.,on-green-high-performance-com puting;-2013-Jun, pp-1-6.

5. NavamaniDJ,-VeenaML,-LavanyaA,-V-ijayakumarK.“-E fficiency-comparison-of-Quadratic-Boost-DC-DC-Conve rter-in-CCM\&-DCM".-International-Conf..,on-Electronic s\&-Communication-Systems;-2015-Jun-pp-1156-61.

6. ChoudhuryTR,-NayakB."-Comparison\&-analysis-of-casc aded\&-Quadratic-boostconverter". -Power-Communication\&-Information-Technology-Con. .,; -2015-Oct. pp.-78-83.

7. PriyaP,-BashaSG, -Niranjan VSV,-SeyezhaiR "-Investigation-of-Sic-MOSFET-basedquadratic-boost-converter-for-photovoltaic-applications". -IJPERA.-2016-Oct-1(3):26-9.

8. HwangJH, -SohJH, -KimYR "-Design-procedure-for-minimizing-conduction-loss-forZCT-PWM-boost-converter".-Future-energy-electronicsconf..,(IFEEC);-2015-Nov-pp--1-6.

9. GhamrawiA, -GaubertJP,

-MehdiD

"-New-control-strategy-for-a-Quadratic-Boost-Converter -used-in-solar-energy-system".-Energy-Conf..,(ENERGY CON);-2016-Apr-pp-1-6.

10. Selvakumar, K., Palanisamy, R., Vijayakumar, K., "Implementation of quasi Z-source 7 level inverter with reduced switches using PV system," Journal of Advanced Research in Dynamical and Control Systems 10(7 Special Issue), pp. 1152-1161 